\title{
Early Highway Failures
}

\author{
Ibrahim Mohamed Ahmed ${ }^{1}$
}

\begin{abstract}
This paper is an effort to share experience with the readers to help in controlling the construction of the on going and future projects. It is seen that most of the newly constructed highways practiced early deterioration of pavements in some of completed sections of these highways, which is a matter of concern. This paper tried to find the reasons of deterioration and come out with some solutions for the problems.

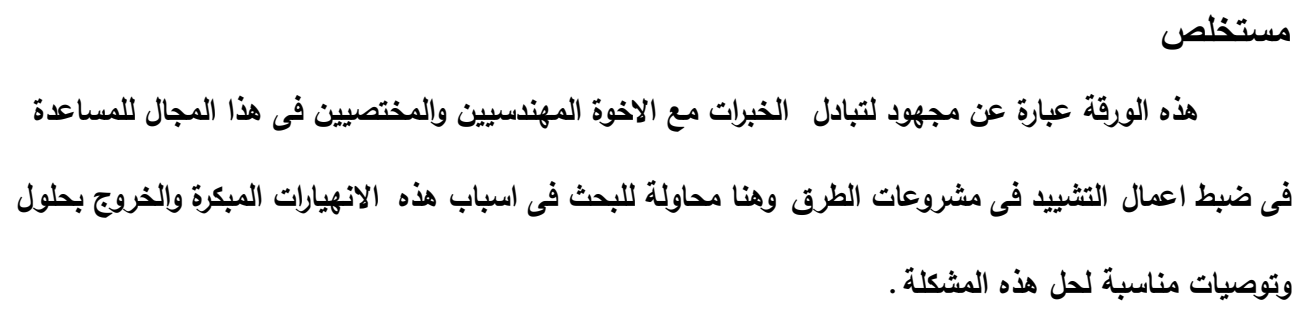

${ }^{1}$ PHD.CE.FSES - Omdurman Islamic University, Sudan. 


\section{Introduction}

The Sudan in the last few years has constructed a number of Roads like: Khartoum - Shandi- Atbara, Omdurman - Eldabba - Dongla, Atbara Haya - Marawi - Karima, Alobeid - Elnuhud, etc. as part of the Development programs, as well as many States roads.

The above ambitious projects contribute immensely to the economic growth of the country and add to our national pride. However, early deterioration of pavements in some of completed sections of these highways is a matter of sad concern. Extensively cracked pavements associated with settlement, rutting, raveling and potholes are a very common observation on the roads.

\section{Design Life and Maintenance Needs}

The flexible asphalt pavement of national highways and state highways are generally designed for a life of 15 years. Sometimes flexible pavements state highways and other roads are designed for a life of 10 years or even lesser.

Similarly, urban roads and expressways are generally designed for a life of 20 years. If good pavement drainage condition is maintained, an adequately designed and constructed pavement should perform its full designing life. Satisfactorily with nominal maintenance, embracing works like application of thin surfacing the periodically of which generally varies from four to 8 years for heavily trafficked roads National highways depending upon rainfall of the area, Suitable overlays triggered by pavement 
deflection measurement can further enhance life of the old pavement for many more years.

The author has to been involved in pavement design work including field data collection in some of the projects besides research work on the area and teaching business.

This paper is an effort to share his experience with the readers to help in controlling the quality of construction of the on going and future projects.

\section{Early Failures: Definition and Characterization}

Failures of pavement structure and its form resulting in increased surface roughness $(\mathrm{mm} / \mathrm{km})$ to the level and at a time that routine and periodic maintenance cannot make the pavement to cater its intended service need for the whole design like has been considered as the case of early failure in this paper. The first rainy season is often the first major test of the pavement structure when major construction deficiencies reflect in the form of settlement and wide cracking, usually longitudinal due to either embankment failure or reflection cracking. Similarly first summer after opening the pavement to full traffic is perhaps the first major test of asphaltic surfacing of its resistance to bleeding and plastic deformation. A pavement that performs well up till second rainy season and second summer most often performs well throughout its design life.

Early failure in asphaltic pavement is generally characterized by surface defects like; cracks of hair line, alligator, longitudinal, traverse and reflection nature; deformation like ratting, slippage, shoving nature, 
settlement and disintegration including stripping, raveling, loss of aggregates and potholing.

\section{Causes of Early Failures}

Asphaltic pavement is a subject of deterioration with time due to wear and tear action of traffic and aging of asphalt and hence requires routine as well as periodic maintenance.

Other factors that contribute to deterioration of pavement are vehicular breakdown and accidents, trafficking of overloaded heavy vehicles, spillage of vehicle oils, burning of fire on pavement, falling of aggregates form Lorries causing abrasion by traffic, scratching of pavement by overhanging reinforcement steel from lorries, etc. however the discussion is presently limited to the following main reason of early failures of pavements:

- $\quad$ Design stage problems.

- Construction stage problems

- $\quad$ Poor pavement drainage and maintenance

- $\quad$ Overloaded traffic.

\section{Design Stage Problems}

Generally, design stage problems may result in reduced life of pavement and distress due to this mistake may appear late, say sometime after expiry of half of the design life. The design stage problems can be subdivided into categories namely:

- Data collection problems. 
- Data interpretation and design problems.

\section{Data Collection Problems}

The pavement design is principally based on assessment of design traffic expressed in terms of million standards Axle (MSA) for the design life. It is based on initial traffic after construction in terms of number of Commercial Vehicles Per Day (CVPD) its growth rate, design life, Vehicle Damage Factor (VDF) and distribution of commercial traffic over the carriage way.

Any mistake in assessment of design traffic, which is based on above information, may adversely affect the design and life of pavement.

California Bearing Ratio (CBR) method for new construction and Benkelman Beam Defection (BBD) technique for overlay design have been the basic methods adopted world wide for designing flexible pavements. For overlay design, error in measurement of pavement defection, pavement temperature, sampling and testing of sub grade soil for moisture content and soil type grading, PI, etc may also affect the pavement design.

\section{Data interpretation for design problems}

While instrumental, observational and personal errors itself can be there in the deflection measurement, logical interpretation of these data and realistic application of various corrections are very important. There is possibility of arriving at un-realistic and incorrect characteristic deflections if temperature and seasonal moisture corrections are not applied correctly and realistically keeping various conditions of the site in view. Pavement 
design based on faulty interpretation of field data and incorrect characteristic deflection can give rise to fault in design, which can seriously affect its life.

\section{Construction Stage Problems}

It is mostly the construction stage problems that result in early failures of asphaltic pavements. The construction stage problems can be sub divided into two categories:

- $\quad$ Material selection problems.

- $\quad$ Construction methods problems.

\section{Material Selection Problems -General}

Soil, rock/gravel and bitumen are the parent materials used in flexible pavement construction.

Various tests are specified and conducted on these materials in individual as well as in their suitable combinations to ascertain their suitability in construction at appropriate levels. Incorporation of any substandard material in individual or in combination may seriously affect the performance of the work.

\subsubsection{Earthwork}

Material problems: The pavement structure is designed based on minimum sub grade strength measured in terms of CBR value for the designed traffic of the corridor. Hence, it is essential to ensure the design CBR at the compaction level (98 per cent) of heavy compaction required to be ensured in the field and not at 100 per cent compaction level, which is 
done in some site laboratories, pavement structure supported on such sub grade meeting CBR requirement marginally at 100 percent. Compaction may perform poorly giving rise to settlement and cracking of surfacing free swelling index (FSI) may be an important determination in cases of clayey soils and incorporating of swelling.

Soil in some top $1 \mathrm{~m}$ depth of earthwork $(50 \mathrm{~cm}$ sub grade and top 50 $\mathrm{cm}$ if embankment) may result in different types of pavement distress such as block, longitudinal and transverse cracking.

Incorporation of unsuitable class, low density and highly heterogeneous soils in respect of (MDD and CBR in sub grade) may behave poorly at the time of rolling and provide non-uniform support to pavement structure and hence can result in surface irregularity due to differential settlement, raveling and cracking of surfacing.

\subsubsection{Granular Sub Base}

a. Material problems: Granular Sub-Base (GSB), generally the first pavement course over sub-grade and extending full formation width, is requirements to fulfill structural / stability as well as functional requirements. For meeting its functional requirement of pavement drainage, its specified grading takes care of intended degree of permeability. Hence ensuring specified grading in work is important from drainage point of view.

For meeting its structured requirement, it is required to possess specified minimum value of CBR based on the type of grading at the field compaction. For this also, meeting the grading required to be sound, durable 
and strong measured in terms of Ten percent Fine Value (TFV) and the fine fraction is required to have Liquid Limit (LL) and Plastic Index (PI) less than the specified maximum. Sometimes lower of PI is also specified to ensure binding property in the mix. Compacted GSB layer with highly plastic binder soil as its ingredient may lack stability in started condition and displace under moving wheel load. The distress appearing due to this sub-base failure may manifest in the form settlement and upheaval.

b. Construction mistake: The GSB materials ingredients are allowed to be mixed mechanically either using a suitable mixing by dozers off road or adopting mix-in-place method and there may be departure of grading from the specified limits at places. Non-homogeneous mix may lack stability due to poor mechanical interlocking, uniformity in drainage characteristics providing unstable and non-draining base for the superimposing granular base course compaction is the important requirement for GSB courses for any other pavement course, and any spot with poor compaction may reflect depression and / or cracks in the pavement.

\subsubsection{Dense Bituminous Courses}

\section{Materials problems:}

(1) Aggregate: On modern projects, necessary testes are generally conducted on aggregates and only conforming materials are proposed for use in permanent works. However, sometimes too flaky and elongated materials are incorporated in works. Such materials break during elastic flexing of the pavement and due the traffic wheel load impact. This opens 
up new unbounded faces in aggregate, which may show up in ratting, raveling and cracking.

Sometimes materials poor in bituminous coating retention are used in work due to uncertainty of the stripping value test result for visual assessment nature of the test. There is necessity of further research to devise a more scientific and standard test to tackle the problem. Polished Stone Value (PSV) is another test recommended for the aggregates to be used in wearing course like BC. This test till recently used to be skipped at most construction sites primarily due testing facility. Polishing of aggregates in wearing course may render the riding surface too smooth making the pavement prone to accidents necessitating early application of renewal course.

(2) Bitumen: Bitumen binder in Sudan imported by various companies. The Government has its quality control laboratories and quality control system in place. Incase of bitumen however there are generally two possibilities of material fault (1) supply or procumbent of the other than the specified grade of bitumen stealthily during the period of scarcity, and (2) adulteration during transportation to construction site, hence testing of materials at site is important. Incorporation of such material in work may seriously affect the durability and performance of the pavement.

(3) Mix Design: Arriving at suitable job mix formula is a very specialized job. Mix design arrived at by Marshall for the further needs to be examined and modified for the environmental and traffic conditions of the site. Improperly designed mix may behave poorly at time of paving and problems like segregation, cracking and slippage may be encountered 
during laying and rolling. Further distresses like flushing (bleeding / fatty surface), rutting, cracking, hungry surface, raveling etc may appear early on opening the surface to traffic.

Farther, it is now well established that dense bituminous courses, which reduce in air void (void in mix) to less than 3\% (approximately) after secondary compaction due to traffic, undergo plastic deformation and deterioration takes place very fast there after. Hence, at the design stage it is desirable to compact Marshall Specimens in laboratory to refusal density, density up to which the mix gets further compacted after several years of trafficking to simulate field conditions after secondary compaction in the laboratory and then to analyze these specimens for air void and other parameters. A minimum air void of 3\% should be ensured at refusal density. This may require repeat of the whole design procedure.

(4) Mix Production: Hot Mix Plants (HMP) need to produce mix closely telling with the job mix formula established in the laboratory. In modern automatic batch type HMP poor proportioning of mix are more in case of continuous type plants. In either case quality of mix may go poor due to:

- Incorrect proportioning of ingredients.

- Inadequate mixing temperature of ingredients and Insufficient mixing ingredients.

Poor quality of mix may pose problems at the time of laying and rolling and cause various imperfections in finished work (see table 1) that may reflect in distresses like flushing, rutting, cracking etc on trafficking. 
(5) Construction problems: Tacking, laying and rolling are part of bituminous construction. Some most occurring laying and rolling mistakes with early distressing potential are discussed below.

\begin{tabular}{|c|c|c|c|c|c|c|c|c|c|c|c|c|c|c|c|c|c|c|c|c|c|c|c|c|c|}
\hline \multirow[t]{6}{*}{ 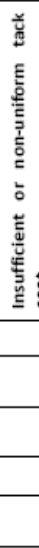 } & & 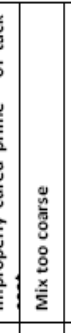 & 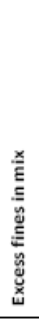 & 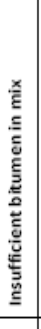 & 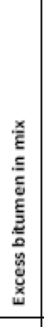 & 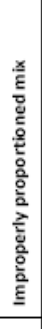 & 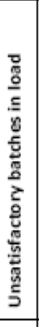 & 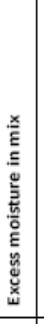 & 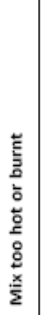 & $\begin{array}{l}\frac{\pi}{0} \\
8 \\
8 \\
\frac{x}{\Sigma} \\
\frac{x}{\varepsilon}\end{array}$ & 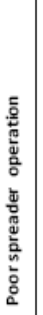 & 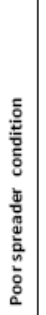 & 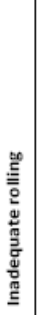 & 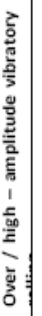 & 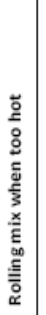 & 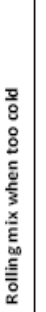 & 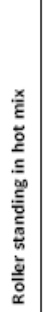 & 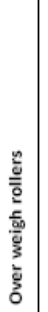 & 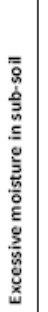 & 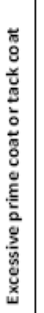 & 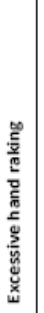 & 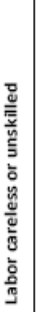 & 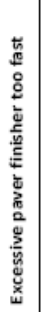 & 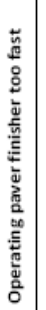 & 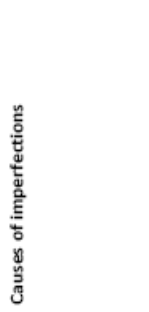 \\
\hline & & & & & & & & & & & & & & & & & & & & & & & & & imperfections \\
\hline & & & & & $\mathrm{x}$ & $\mathrm{x}$ & $x$ & & & & & & & & & & & & & $\mathrm{x}$ & & & & & $\begin{array}{l}\text { Bleeding / } \\
\text { Flushing }\end{array}$ \\
\hline & & & & $\mathrm{x}$ & & & & $\mathrm{x}$ & $\mathrm{x}$ & & & & & & & & & & & & & & & & $\begin{array}{l}\text { Brown, dead } \\
\text { appearance }\end{array}$ \\
\hline & & & & & $x$ & $\mathrm{x}$ & $\mathrm{x}$ & & & & & & & & & & & & & & $\mathrm{x}$ & & $\mathrm{x}$ & & Rich of fatty spot \\
\hline & & $\mathrm{x}$ & $\mathrm{x}$ & & & $\mathrm{x}$ & $\mathrm{x}$ & & & $\mathrm{x}$ & $\mathrm{x}$ & $\mathrm{x}$ & $\mathrm{x}$ & $\mathrm{x}$ & $\mathrm{x}$ & $\mathrm{x}$ & & & & & $\mathrm{x}$ & $\mathrm{x}$ & $\mathrm{x}$ & $x$ & $\begin{array}{l}\text { Poor surface } \\
\text { texture }\end{array}$ \\
\hline$x$ & $\mathrm{x}$ & $x$ & & & & $x$ & $x$ & & & $x$ & $x$ & $x$ & $x$ & $x$ & & $x$ & $x$ & $\mathrm{x}$ & $\mathrm{x}$ & & $x$ & $\mathrm{x}$ & $\mathrm{x}$ & $x$ & $\begin{array}{l}\text { Rough uneven } \\
\text { surface }\end{array}$ \\
\hline$x$ & $\mathrm{x}$ & $\mathrm{x}$ & & & & $x$ & $\mathrm{x}$ & & & $\mathrm{x}$ & $x$ & $x$ & $x$ & & & $\mathrm{x}$ & & & & & $x$ & $x$ & $\mathrm{x}$ & & $\begin{array}{l}\text { Honeycomb or } \\
\text { raveling }\end{array}$ \\
\hline & & $\mathrm{x}$ & & $\mathrm{x}$ & & $\mathrm{x}$ & $\mathrm{x}$ & & & $\mathrm{x}$ & $\mathrm{x}$ & $\mathrm{x}$ & $\mathrm{x}$ & & & $\mathrm{x}$ & & & & & $\mathrm{x}$ & $\mathrm{x}$ & $\mathrm{x}$ & & Uneven joint \\
\hline & & & & $x$ & & $x$ & $\mathrm{x}$ & & & $x$ & $\mathrm{x}$ & & & $x$ & & $\mathrm{x}$ & $x$ & $\mathrm{x}$ & $\mathrm{x}$ & & & $x$ & & & Roller marks \\
\hline $\mathrm{x}$ & $\mathrm{x}$ & $\mathrm{x}$ & $\mathrm{x}$ & $\mathrm{x}$ & $\mathrm{x}$ & $x$ & $\mathrm{x}$ & $\mathrm{x}$ & & & $\mathrm{x}$ & $x$ & & & $\mathrm{x}$ & & & $\mathrm{x}$ & & $\mathrm{x}$ & $\mathrm{x}$ & & & & $\begin{array}{l}\text { Pushing or wavy } \\
\text { finish }\end{array}$ \\
\hline & & & $\mathrm{x}$ & $\mathrm{x}$ & & $\mathrm{x}$ & & & & & & & & $\mathrm{x}$ & $\mathrm{x}$ & & & $\mathrm{x}$ & $\mathrm{x}$ & & & & & & Many fine cracks \\
\hline & & & & & & & & & & & & & & $\mathrm{x}$ & & & & $x$ & $\mathrm{x}$ & & & & & & Long deep cracks \\
\hline & & $\mathrm{x}$ & & & & $\mathrm{x}$ & & & & $x$ & $\mathrm{x}$ & $\mathrm{x}$ & & $\mathrm{x}$ & $\mathrm{x}$ & & & $\mathrm{x}$ & & & & & & & $\begin{array}{l}\text { Crushing of } \\
\text { aggregates }\end{array}$ \\
\hline & & $\mathrm{x}$ & & $\mathrm{x}$ & & $\mathrm{x}$ & & & $\mathrm{x}$ & $\mathrm{x}$ & $\mathrm{x}$ & $\mathrm{x}$ & & & & & & & & & & & $\mathrm{x}$ & $\mathrm{x}$ & Tearing of surface \\
\hline $\mathrm{x}$ & & $x$ & $x$ & & $x$ & $x$ & & $x$ & & $x$ & & & $\mathrm{x}$ & $\mathrm{x}$ & & $\mathrm{x}$ & & $x$ & $\mathrm{x}$ & $\mathrm{x}$ & & & & & $\begin{array}{l}\text { Mix slipping on } \\
\text { base }\end{array}$ \\
\hline
\end{tabular}

(6) Laying: Non-uniformity of surface texture along and access the carriageway can be seen on many freshly constructed pavements. Segregated coarse spots are prone to raveling and generally porous which allow ingress of water during rains making sub grade and pavement structure weak. Increase pore water pressure due interconnection and magnification of voids and early hardening of bitumen forming potential spots of cracking and potholing. Segregation also causes departure of the 
mix from the designed grading. Portion of mix gone finer due to segregation may also result in loss of stability and increased flow, which is single enough case for shoving and deformation of the bituminous layer. Hence segregation should be prevented right from the stage of mix collection in haul vehicle till its paving thorough the stages of transportation and feeding to paver.

However, segregation takes place during paving at most of the construction sites due to "start and stop" -way of paving, non-steady material feed to the paver, untimely and in adequate operation of wings of the hopper, poor condition of paver and / or its screed etc making the work prone to early distressing.

(7) Rolling: this is the most important activity in paving of bituminous mix. Imperfection like rolling cracks and bumps, open longitudinal and transverse joints, material crushing and slippage, rolling marks, rough surface etc, are often seen on freshly finished bituminous works.

Rolling at correct temperature is very important. Hot mix roller at low temperature may be poor compaction and stability due to poor material interlacing and show up in coarse textured surface prone to raveling and cracking.

Similarly rolling at very high temperature may result in slippage and cracking of the layer. Layer may also crack and aggregates may get crushed due to rolling with steel drum / tandem roller in high amplitude vibratory mode especially on thin asphalt lifts. While aggregates crushed during rolling, make the layer prone to early disintegration, cracked asphalt if not redone forms potential spot for early potholing. 
Due to ignorance about correct rolling pattern, rolling at times is started from higher level and advanced to wards lower level across the road. This may result in opening up of the longitudinal joint and spreading of the material beyond the pavement edge, which may be associated with cracking in some cusses leaving room for water ingress.

Sometimes the hot mix gets pushed ahead of the roller drum during breakdown rolling resulting in rolling bump at places. This may happen due to many reasons (table 1) including fast, incorrect pattern and direction of rolling.

Due to improper adjustment and functioning of water, spray nozzles, surplus water from steel drums and pneumatic treys of the roller is often seen to fall on to the hot asphalt mix in may cases. This hardens the asphalt and makes the mix stiff, which results in inadequate compaction, rough texture and high percentage of air voids the layer rendering it prone to early cracking. Also, this water ingress into the roller-induced cracks and doesn't let the mix to close up during various stages of rolling and cracks finally stay in the work.

The scrapper / waffling pads in many cases do not touch and wipe the rolling surfaces and roller-picked material usually causes the abrasion of the surface rendering it rough and prone to raveling. Some hireling rolling cracks get closed up during movement of traffic; however, it may not happen so in cases cold areas, winter paving and immediate onset of rains after paving. Obviously, the consequences distress prone surfacing. 


\section{Construction Methods Problems-General}

Even good materials in individual as well as in combination may fail to perform up to their potential if not constructed properly. In this regard, execution methodology, construction equipment work planning and sequencing, experience and knowledge of the job, dedication to work and working environment are all equally important.

Our main aim here is to highlight the construction stage mistakes that result in early failures of pavement, for the benefit of the engineers, technicians and all others engaged at road construction work. Comming paragraphs highlights the most occurring construction mistakes at most sites. Different items of work have been taken up separately for discussion.

\subsection{Construction Problems}

Construction on well-prepared, compacted and shaped foundation in layers not exceeding the specified compacted thickness (which depends on weight and type of the compaction equipment and soil), adequate compaction of all the layers right from foundation level in sufficient width to allow for slope trimming after construction and compaction at moisture contend (OMC) are key to quality construction. Wide longitudinal (tension) cracks on high embankments due to inadequate compaction of lower layers up to the towline have bean seen at many construction sites.

Oversize stones with soil carry most of the load of steel drum roller during rolling and do not let the soil around get compacted uniformly to the desired degree. All holes resulting from removal of big sized stones and compaction test holes be filled and compacted with extra quantity of soil before 
spreading material for the construction of next layer. Negligence on above, which is mostly the case, may reflect in the form of tiny settlement and cracking in the pavement. It is very important for the sub grade top to be smooth, free from any potential spot for water logging and having required cross slope camber to affect efficient drainage in the event of any ingress of water, failure of which may weaken the sub grade and may result in pavement settlement and alligator cracking.

\section{Poor Pavement Drainage and Maintenance}

Drainage is very important in long-term serviceability of the flexible pavement. There are numerous examples of early distress primarily due to inadequate and in efficient pavement drainage. Poor construction or any compaction or material deficiency adds to early pavement distress due to poor condition of drainage. Stagnation of water on or adjacent to pavement courses it may cause stripping of asphalt from aggregates, early hardening of asphalt, settlement and development of pone water pressure under heavy traffic. These conditions may result in development of hairline and alligator cracks, raveling, disintegration and potholing surfacing. Hence, it is essential to attend drainage needs properly during pavement maintenance.

\section{Overloaded Traffic}

Depending upon its number of axles the maximum permissible load to be carried by a comical vehicle is specified. This limits the axle load (or precisely wheel pressure) to a standard axle load for which the pavement is designed. However, different traffic and axle surveys carried out in the 
country recently reveal the fact that excessively by the designer by taking realistic value of VDF, can cause overloading regulation being in-place. This through can be taken care of excessive overstressing and hence failure of pavement.

\section{Conditions Responsible For Construction problems}

Often construction engineers, supervisor and machinery operators engaged at several of works are in adequately trained and experienced. Consciousness for quality and knowledge of consequences of improper construction are often missing in them. Frequent change of workers also affects the work. Deployment of poorly maintained machinery and their breaking down during working often results in inferior quality of work.

Many contractors are poor in planning and sequencing of activities, which often causes excess slippage in progress.

Some contractors have made it a poling to progress the work slow till they get relaxed standards of testing and that most of the progress is achieved in last third or last quarter of the project period.

The pavement starts getting distressed during very first rainy season and subsequently early with passage of time.

Patching of newly constructed roads starts from the very first year of its completions giving jerk, ride to the road users.

\section{Conclusions}

Early failure pavements are a matter of great concern.

These failures may occur due to: 
a. Design stage mistakes.

b. Construction stage mistakes.

c. Poor pavement drainage mistakes.

d. Maintenance problems.

e. Trafficking of overloaded vehicles.

Care should be taken to a void these mistakes as stated in the paper avoiding the early failure of our pavements and quality control is required during all stages.

\section{References}

[1] MORT and H, "Specifications for Road and Bridge Works" 2001 (Fourth Revision).

[2] The Asphalt Institute, Manual Series No.2 (MS-2) Mix Design Methods for Asphalt Concert and other Hot-Mix Types", $6{ }^{\text {th }}$ Edition Lexington 1994

[3] The Asphalt Institute, Manual Series No.8 (MS-8), Asphalt Paving Manual" $3^{\text {rd }}$ Edition 1978.

[4] The Asphalt Institute, Manual Series No.22 (MS-22) Principles of Construction of Hot-mix Pavements", 1983.

[5] BS598; Part 104 "Methods of Test for the Determination of Density and Compaction", 1989.

[6] BS 812, Part 111“Method for Determination of Ten percent Fines Value" 1975. 